\title{
LA INTERCULTURALITAT A LA LITERATURA INFANTIL I JUVENIL CATALANA
}

\section{INTERCULTURALITY IN CATALAN CHILDREN'S AND YOUNG PEOPLE'S LITERATURE}

\author{
Xavier Mínguez-López \\ Universitat de València \\ xavier.minguez@uv.es
}

Resum: Aquest article analitza la presència de la interculturalitat en la literatura infantil i juvenil (LIJ) escrita en català en els anys 2002-2006, un període d'especial augment de la immigració i també dels debats sobre l'educació intercultural a casa nostra. L'estudi, fet a partir d'un corpus de 95 llibres triats a través de l'encreuament de diversos factors de selecció (premis literaris, llistes de recomanació i ressenyes positives), permet acostar-nos al tema de la diversitat cultural expressada des d'una perspectiva àmplia. Com a conclusió, però, considerem que la LIJ catalana del període estudiat no dóna compte d'aquesta diversitat cultural. Ni la ja existent, ni la creada per les noves condicions socials. Finalment, proposem una llista de llibres multiculturals i una altra de llibres interculturals de cara al seu aprofitament didàctic.

Paraules clau: literatura infantil i juvenil catalana, interculturalitat, multiculturalitat, educació literària, diversitat cultural, literatura de minories, cànon literari, globalització.

Abstract: This paper analyses the multiculturalism in children's and young people's literature written in Catalan between 2002 and 2006, a period when there was a marked increase in immigration and the debate about intercultural education became more intense. The study focuses on a corpus of 95 books selected according to different factors (namely, literary awards, positive reviews and recommendation lists). This enables a broad approach to be taken on the issue of cultural diversity. It must be pointed out, however, that the Catalan children's and young people's literature analysed does not reflect this period of cultural diversity. Including both the diversity already and that resulting of the new conditions created by changes taking place at the beginning of the century. Finally, a list of multicultural books and a list of books that can be used as teaching tools for intercultural education is suggested. 
XAvier Mínguez-López

La interculturalitat a la literatura infantil i juvenil catalana

Key words: Catalan Children's and Young People's Literature, interculturality, multiculturality, literary education, cultural diversity, Minorities Literature, literary canon, globalisation.

\section{$\cos \cos$}

\section{INTRODUCCIÓ: OBJECTIUS, METODOLOGIAI HIPÒTESIDE PARTIDA}

La nostra societat ha experimentat un gran canvi arran dels moviments migratoris dels anys 90 i els primers 2000. L'arribada massiva de ciutadans d'altres països a les nostres terres va emfasitzar la multiculturalitat ja existent $i$, d'alguna manera, va demanar que els agents educatius prengueren nota i reforçaren l'anomenada educació intercultural. D’altra banda, els canvis també haurien de fer esperar que la literatura en general, i la literatura infantil i juvenil (LIJ) en particular, els reflectiren. És per això que duguérem a terme aquesta investigació que tenia com a objectiu principal detectar la interculturalitat present (i absent) a les obres de LIJ en un període especialment important per a l'arribada de nouvinguts. També ens plantejàvem analitzar de quina manera es donava aquesta interculturalitat i en quina mesura podíem parlar d'una literatura intercultural (i multicultural) o no.

La nostra investigació comença amb la confecció d'un corpus de 95 llibres. ${ }^{1}$ Aquesta xifra ens semblava bastant rellevant per a poder extraure'n conclusions. El corpus volia ser una dissecció de la literatura publicada entre l'any 2002 i 2006 (tots dos compresos) de manera que, en lloc de fer una cerca de llibres o autors concrets, vam preferir elaborar el corpus tot creuant diverses fonts com els premis literaris, la selecció en llistes d'honor i les ressenyes positives en revistes especialitzades (CLIJ i Faristol). Vam ser especialment conscients de respectar l'equilibri entre territoris del domini lingüístic així com la proporció de franges d'edat. Aquesta confecció del corpus permetia una mirada més o menys coherent a la LIJ produïda en aquell període i amb diferents fonts que asseguraven, amb les evidents desviacions, una tria d'obres de qualitat. Lúnic element que mancava en aquests criteris era la presència del lector i l'èxit de les obres. Malgrat això, creiem que les 95 obres seleccionades són plenament representatives del període tot i que, evidentment, comporten determinades limitacions. Per exemple, el gènere majoritari en el corpus era el narratiu, ja que hi ha pocs

I. Inicialment es tractava d'un centenar, però atesa la caducitat dels llibres infantils i juvenils, vam haver de renunciar a arribar a aquest nombre en el període triat. 
premis d'altres gèneres i la crítica tampoc no n'ha destacat. Així, tan sols trobem dues obres poètiques i no hi ha cap assaig.

Respecte dels ítems valorats, vam partir d'una visió àmplia tant del concepte de multiculturalitat com d'interculturalitat. D'aquesta manera incloem bàsicament cinc apartats generals: a) si apareix reflectida la nostra societat multicultural al llibre, b) si apareix un personatge d'origen estranger, $c$ ) si parla d'una comunitat d'estrangers en un país europeu, $d$ ) si es tracta d'un relat sobre una cultura estrangera o, fins i tot, $e$ ) si es tracta d'un relat sobre un grup social marcat com puguen ser els homosexuals, les dones com a col-lectiu, la gent gran, etc.

La presència i/o absència d'aquests ítems ens proporcionà unes dades que ens permetien fer percentatges. En un estudi literari, però, el biaix quantitatiu no resulta un mètode òptim de recerca, de manera que com a metodologia fonamental férem servir l'anàlisi crítica tot partint d'aquests ítems. En tot cas, els percentatges que aconseguírem ajuden a comprendre l'abast d'alguns fenòmens; és per això que no hi hem renunciat.

Finalment, la nostra hipòtesi de partida - tenint en compte un estudi anterior (Mínguez 20Io) - era que la presència de la societat multicultural i de la interculturalitat a les obres estudiades no estaria a l'altura dels processos viscuts per la nostra societat. Així, pensàvem que la LIJ catalana tindria més interés a reivindicar la cultura pròpia que a difondre les alienes.

\section{MARC TEÒRIC}

No ens detindrem especialment en aquest apartat ja que considerem que l'anàlisi del corpus és molt més important. No obstant això, haurem de parlar, ni que siga succintament, de dos aspectes. D'una banda, el concepte de cultura. Hem de tenir en compte que treballem amb una activitat artística com és la literatura, de manera que vam incloure les qüestions referents al cànon tant de la literatura en general (Bloom I995, Sullà 1998) com de la LIJ en particular (Del Amo 2003, Hunt 2003, McGillis 2003). També vam estudiar el circuit cultural, en especial els canvis que hi ha imprés la globalització (Morin 20I0, Tomlinson 200I) o el sistema literari (Bourdieu I99I, Even-Zohar 2005, Shavit 1986). Com que volíem centrar-nos en la qüestió de la interculturalitat, ens interessava saber dels usos, costums o hàbits, però també d'aquest anecdotari de la vida quotidiana que constitueix igualment la cultura i que, sovint, comporta xocs rellevants entre persones de diferents cultures. Encara més, entre persones que se suposa que pertanyen a la mateixa cultura. Pot ser el cas del rebuig d'uns col-lectius a uns altres (l'homofòbia, per posar-ne un exemple).

Caplletra 61 (Tardor, 2016), pp. 61-89 
Xavier Mínguez-López

La interculturalitat a la literatura infantil i juvenil catalana

Així assumim les idees que recull Jiménez Gámez (2004) respecte a la cultura i també les síntesis d’Hernández (Ariño 1997, Ariño 2002, Hernández 2002).

Per al concepte d'educació intercultural i interculturalitat, prenem com a base els treballs d'Abdallah-Pretceille (1996, 200I), però també Margarita Bartolomé (2002), Teresa Aguado (2003), Xavier Besalú (2002, 2007), novament Jiménez Gámez (2004) $i$ altres. Per a aquests autors hi ha una sèrie d'idees bàsiques que podríem resumir en aquesta citació (Mínguez 2013: 330):

La interculturalitat suposa un acostament a l'altre com a ésser diferent a un mateix, però no condicionat exclusivament pel seu origen cultural. Entre altres coses perquè per definir un individu a través del seu origen cultural, hauríem de definir abans el concepte de cultura o el d'identitat, tots dos com hem vist, plens de matisos. Suposa, doncs, un intercanvi on no sols hi ha aculturació del més dèbil sinó que es produeix un enriquiment mutu fruit de la comunicació i del coneixement de l'altre.

Caldrà doncs, diferenciar-la de la multiculturalitat, que consisteix en la copresència de diverses cultures en la mateixa societat, i del multiculturalisme, que seria la plasmació institucional de diversos països, sobretot els EUA i la Gran Bretanya, d'una política multicultural (Kymlicka 1996, Banks 1997, Abdallah-Pretceille 200I, Banks \& Banks 200I, Jiménez Gámez 2004). En termes generals, es podria dir que tota societat és multicultural (en tant que diversa culturalment), però que no sempre s'hi dóna una relació intercultural, de comprensió i assumpció de l'altre.

\section{EL NOSTRE ESTUDI}

El primer que podem afirmar és que una gran majoria de les obres estudiades tenen alguna relació amb els conceptes que estudiem, un $70 \%$. Cal recordar, però, que la nostra concepció de la multiculturalitat és molt àmplia i inclou diversos apartats. Així, és difícil que els llibres no reflectisquen d'una manera o altra bé la interculturalitat, bé la multiculturalitat, bé ambdues.

Però veiem els ítems de manera individual.

\section{I LA PRESÈNCIA DE LA SOCIETAT INTERCULTURAL I MULTICULTURAL}

Per començar, volíem valorar la presència de la societat multicultural a la LIJ catalana i en aquest sentit marcàrem les obres que donaven una visió polièdrica de la nostra societat amb la presència de col-lectius diversos, tant estrangers, com autòctons. Vam fer incidència en aquelles obres que, per exemple, no es limitaven a presentar 
escoles amb xiquets valencians, catalans o mallorquins, sinó que feien l'esforç de reflectir l'efecte de la immigració de la qual parlàvem adés. Com que es tracta de LIJ, i la presència de la fantasia era previsible, també vam donar cabuda en aquest ítem a aquells llibres que presentaven societats que es podien considerar multiculturals per la seua composició, encara que no concordaren amb societats convencionals. En aquest punt, doncs, vam valorar especialment si els llibres tractaven de mostrar societats complexes o es limitaven a mostrar clixés monolítics i vam fer una lectura intercultural, a la manera de Ming Shui Cai (2002).

El resultat d'aquest primer ítem, tenint en compte com d'ampli és el concepte, és bastant decebedor ja que només un $40 \%$ de les obres estudiades mostren aquesta societat multicultural en alguna de les seues facetes. Si considerem que el corpus se situava durant els anys de creixement de la immigració, juntament amb la diversitat que mostra qualsevol societat i que es pot reflectir en la literatura de múltiples maneres, ens sembla que aquesta xifra queda lluny del que s'esperaria d'una literatura moderna ancorada en la seua societat. El percentatge, si bé no pot representar amb exactitud la presència, dóna compte d'una tendència a ignorar aquests enfocaments. Cal recordar també que el nostre corpus són obres seleccionades d'una manera o altra per la crítica, la qual cosa implica que exclou més que inclou.

Una de les formes de mostrar la multiculturalitat són els llibres corals amb multitud de personatges, tant si en contenen un de central com si no. És el cas d'Anem, Gruny (Ginesta 2002) que parteix d'una parella ben curiosa formada per una xiqueta i un porquet. Creiem que ací l'autora volia fugir dels estereotips sense importar si es considera Gruny una mascota o si es considera un igual de la protagonista. A més a més, en la seua passejada per un paisatge obert, es troben amb diversos personatges de rondalla amb les seues característiques diferencials. També a L'escola secreta de Madame Dudú (Colom 2002) hi ha un gran desplegament de personatges diversos, des d'un massai africà fins al president de la república francesa, tot passant per un pintor italià. A Gent de pedra (Huertas 2003), malgrat situar-se en una època pretèrita, els col-lectius que hi apareixen fan gala d'una certa diversitat, ja que s'hi mostren diferents oficis, diferents tradicions, cultures i maneres d'entendre el món. De fet, el relat no deixa de ser la descoberta d'una altra cultura per part del protagonista.

Atenció especial mereixen els llibres de García Llorca, que acostumen a mostrar un mosaic de personatges diversos amb problemàtiques i motivacions també diverses. És antològic el ventall de personatges tavernaris que fan aparició a Terramolsa (García Llorca 2004), tot lligant el món de les faules i rondalles amb els dels bandolers i bandits. A Terramolsa els homes conviuen amb tota mena d'animals (raboses, gossos, gats, cabres...), amb criatures de la natura (en Bufim-Bufaina, en Hivern Hivernàs...) 
Xavier Mínguez-López

La interculturalitat a la literatura infantil i juvenil catalana

i fins i tot amb criatures fantàstiques com el Cormort. Cadascú en aquest país fictici segueix el seu camí i tracta de sobreviure com pot. A Història d'un cap tallat (Garcia Llorca 2004), en canvi, tan sols hi ha un personatge fantàstic que és la mateixa xiqueta escapçada. La resta del poble, però, hi apareix retratat en la seua diversitat: els segadors, els rics, els grangers, etc., amb la qual cosa el lector hi pot apreciar les diferències entre les persones que componen un collectiu, que sovint es tracten de manera més simplificada.

D’una manera semblant, també els llibres de Miquel Desclot mostren collectius diversos que conviuen pacíficament amb la seua diversitat. Les escombraries que coneix Aristòtil a Aristòtil i les escombraries (Desclot \& Galí 2004) tenen diferents provinences i conviuen a l'abocador, de la mateixa manera que els insectes del circ de Nas de barraca (Desclot \& Jover 2004), que s'ajunten també d'una manera casual i organitzen les seues aventures. Un exemple paradigmàtic de llibre coral és Ens barregem (Juanolo 2006), on els personatges se succeeixen plana rere plana i mostren la diversitat de la nostra societat.

La interpretació d'aquestes societats multiculturals que no es corresponen amb la nostra realitat, creiem que resulta molt encertada en llibres com El darrer manuscrit (Galícia 2005). Des del nostre punt de vista, la novel.la mostra un futur multicultural que resulta facilment identificable amb el nostre present, ja que tambése cita la presència omnipotent de les multinacionals que ja han dut a terme una globalització efectiva, fins i tot, fora de les fronteres terrestres. Els acrians i ratmanites es resisteixen a aquest domini, però són anihilats de la mateixa manera que els gotxis, criatures semihumanes que són arrasades per ser incompresos pels humans. En aquest cas, la identificació amb els problemes de la societat multicultural actual és molt senzilla, malgrat que l'autora tria l'espai exterior per tal de posar en joc aquests xocs culturals. Així mateix, també la interculturalitat és palesa en tant que tota la fauna que pul.lula per les pàgines es veu obligada a relacionar-se. En tot cas, és una interculturalitat forçada i poc viscuda. Hi ha sempre una gran desconfiança entre les diferents cultures que hi apareixen.

És un ambient semblant al que es viu, en aquest cas a l'estranger, en concret a la sabana africana, on s'esdevé la història d'Animals! (Bolta \& Ruiz 2002), que també mostra una societat polièdrica amb una gernació d'animals de tota mena que s'uneixen per tal de rebre i assumir les conseqüències de la visita dels humans. El lideratge d'aquesta societat diversa és assumit per dos animals poderosos com són la lleona i l'elefanta que tracten d'equilibrar els diferents punts de vista i també d'imposar la pau necessària entre animals, habitualment rivals, per tal d'arribar a acords. Els humans aconsegueixen dividir els animals tot comprant-los amb ofertes que semblen comoditats en un primer moment, tot i que a la fi es revelen com a paranys, per a ells que han de treballar per mantenir-les. 
La multiculturalitat que mostra aquest llibre, com en el cas anterior, és complexa, amb rivalitats inevitables i conflictes més o menys constants, encara que tots dos llibres reclamen un espai per a la negociació, per a la resolució dels conflictes de manera no violenta.

Allò que realment escasseja en la tria són llibres que mostren la nostra societat actual des d'una perspectiva multicultural i, de passada direm que, natural. Kor de parallamps (Sotorra 2006) parteix del personatge de Yung-Lluna, una xiqueta d'origen xinés adoptada. Aquesta xiqueta no sols té un origen estranger que els trets físics li fan impossible d'amagar, sinó que s'emmarca en un context on també apareixen xiquets provinents d'altres països, com el xiquet africà amb qui fa amistat a la fi de la novel.la. D'una forma semblant, el protagonista d'Un haiku per l'Alícia (Miralles 2002), acudeix a les reunions del club de les bones sensacions, on es troba amb Alícia, una ucraïnesa que resideix de forma il.legal al país, però també amb Lucien, un jove canadenc. Francesc Miralles explota la qualitat cosmopolita de Barcelona sense grans dificultats i tampoc sense incidir-hi. En una ciutat com Barcelona és facil coincidir amb estrangers. El que és quasi impossible és no coincidir-hi mai.

Així també, El misteri de les quatre punyalades (Hernàndez 2005) mostra una Catalunya amb elements multiculturals. El protagonista es declara amic dels estrangers humils amb els quals manté una relació llarga que s'allunya dels tòpics de les relacions de conveniència. També els fa aparéixer en contextos de normalitat, sense emfasitzar la seua condició d'immigrants. Malgrat aquests aspectes, cal dir que la trama continua focalitzada en una xiqueta de classe alta i la resta de personatges de classe mitjana. En tot cas, el narrador ajuda a crear una imatge positiva dels immigrants, tot i que ocupen treballs associats a la seua condició d'immigrants (artesania i restauració).

Aquestes tres novel.les són les úniques que fan un esforç per fer veure una societat més polimòrfica des del punt de vista cultural. Potser podríem incloure-hi també $M . A$. X. (Burgas 2004), però cal tenir en compte que està ambientada en el futur, amb la qual cosa la identificació amb la nostra societat immediata no és tan directa com succeeix amb obres ambientades en el nostre temps. A diferència d'El darrer manuscrit, el llibre no crea una realitat paral.lela sinó que es basa clarament en la nostra. De fet, es pot col-legir dels ambients multiculturals (que es dedueixen pels noms estrangers dels companys de l'institut) que aquest és el futur que ens espera, però no s'acaba d'afirmar que és el present que vivim. La multiculturalitat, com diem, és un tret característic d'aquesta societat del futur, també a la part virtual, on els adolescent introdueixen personatges estrangers en la configuració del joc. De tota manera, com que bona part de la trama és el mateix joc, aquesta multiculturalitat és tangencial. Protagonista i coprotagonista són personatges autòctons i són el centre de la trama que es desenvolupa a mitges entre la realitat física i la realitat virtual.

Caplletra 61 (Tardor, 2016), pp. 61-89 
XAvier Mínguez-López

La interculturalitat a la literatura infantil i juvenil catalana

Per veure aquesta societat polimòrfica caldrà anar-se'n al passat. Així, a L'esclau del Mercadal (Garcia i Cornellà 2004) la multiculturalitat és el fil conductor del llibre, que mostra la Catalunya del segle xIV dividida per les tres grans religions amb importants tensions entre elles. El missatge del llibre advoca per la interculturalitat, ja que, de fet, mostra l'amistat entre uns joves més units per la seua qualitat d'adolescents que separats per les religions i els costums. Els exemples són molt nombrosos:

—Només m’empipa perquè avui és dissabte — va murmurar en Jucef de cop i volta, com si un pensament inoportú l'acabés d'assaltar.

-I què passa perquè avui sigui dissabte? - li va preguntar l'Hug.

—El dissabte és el dia sagrat dels jueus. Sembla que baixis de l'hort. Això que fem està sempre malament, però els dissabtes, més.

- Per a mi, seria pitjor si fos demà. Me n’hauria d'anar a confessar de seguida, abans de la missa del diumenge. Ja sou ben estranys, els jueus — va rumiar l'Hug tot mirant en Jucef -No podeu fer festa i resar els diumenges, com fa tothom?

Però aviat van deixar de banda les diferències que separaven les dues societats i les objeccions morals que aquella petita bretolada els podia ocasionar. (p. 23)

En aquell temps, jueus i cristians coexistien força pacíficament i sovint feien negocis o se'ls veia parlar pel carrer o, fins i tot, en alguna taverna. (p. 23)

Aquesta multiculturalitat, però, conté els gèrmens de la societat actual, ja que l'autora no s'està d'afirmar que:

En Bernat, [...] tenia un dubte molt gros: no sabia què li feia més ràbia, si veure com li robaven les cireres o constatar que un dels qui ho feia era un jueu [...] Des de petit, havia alimentat la malvolença que havia aprés a casa seva contra aquella gent que vestia, matava el bestiar, feia pa, menjava, resava, creia, es rentava i, en definitiva, vivia d'una manera diferent, tot i fer-ho en la mateixa ciutat. Compartien la llengua, això, sí, tots parlaven català [...] (p. 3I)

Per molt diferents que siguen els personatges, hi ha una cosa que està per damunt de tots ells com és la llengua i, indirectament, suposem que la cultura catalana. Sense arribar a ser una manipulació històrica, podríem dir que aquest biaix és intencionat. Es veu de manera més palesa a Un riu d'espigues (Ballart 2005), on el tractament de la interculturalitat es veu en la convivència més o menys pacífica de les diferents cultures presents a l'època ibera. Trobem, però, que l'autor fa una interpretació molt estàtica de la cultura $\mathrm{i}$ atorga als ibers unes qualitats patriòtiques que probablement no foren tals. També s'hi fan moltes proclames a favor de la llibertat i en contra de la tirania romana, amb la qual cosa hi ha una lectura partidista de la història. En aquesta lectura partidista es pot llegir un paral-lelisme no massa llunyà a la globalització $\mathrm{i}$ als fenòmens imperialistes. De la mateixa manera, sembla que l'autor tracte els ibers com els primers catalans de la història i en reivindica la cultura davant de l'aculturació que suposa la submissió a l'imperi romà. 
Aquesta catalanització de la història no creiem que manipule els fets històrics, sinó que els llegeix d'una manera particular. Antoni Oliver, per exemple, fa un retrat molt multicultural de la Mediterrània del segle XVII a El silenci del mariner (2002). A la novel-la apareixen nombroses referències al món multicultural de l'època, però molt marcat per la rivalitat entre cristians i musulmans i entre els mercaders d'esclaus d'una banda i altra. Hi ha diverses referències al fet que som iguals i que tots dos bàndols es comporten de la mateixa manera, encara que la sensació final, com que es narra des del punt de vista del mariner, acaba sent una visió negativa dels musulmans. Aquest fragment mostra les reflexions dels personatges al voltant del tràfic d'esclaus:

Més tard baixaren els esclaus turcs per ésser portats als banys, que era el lloc on estaven reclosos. Allà, alguns esperarien un rescat que els alliberàs, d'altres correrien la mateixa sort que la meva: galeres. Era exactament la mateixa escena que la d'Alger. La gent del carrer també els insultava mentre caminaven engrillonats.

Aquí fou quan definitivament em vaig adonar que la pirateria era simplement un negoci que tothom practicava, fossin ara cristians o fossin musulmans. La idea que els únics éssers malvats eren ells era una farsa. Molta gent s'embutxacava diners en l'extorsió. (p. Io9)

Si en aquest llibre el punt de vista podia fer un efecte lleugerament antimusulmà, l'altre llibre d'Oliver del nostre corpus fa l'efecte contrari. Al Razhes, el metge de la talaia (Oliver 2006) és, precisament, un relat centrat en la saviesa mèdica del món musulmà també al segle Xvir. El llibre és multicultural en tant que mostra una Mediterrània creuada per les diverses cultures, tot i que enfrontades. De totes les terres descrites, destaca Istanbul com a una de les localitzacions més multiculturals amb diverses cultures que hi conviuen en la seua qualitat de port internacional:

Istanbul, l'antiga Constantinoble, era una ciutat immensa. Hi vivien més de setanta mil ànimes i s'hi mesclaven moltes races. La ciutat era una mescla d'esglésies i mesquites. Durant segles havia estat el bressol del coneixement i de la saviesa. L'Imperi de Bizanci l'havia fet gran, fins que les creuades del s. XIII l'enfonsaren i l'enfosquiren.

Però ara tornava a viure dins de l'esplendor i era la capital de l'Imperi otomà, que dominava més de mig Mediterrani. (p. II4)

Com diem, la visió de la cultura musulmana és molt positiva ja que, malgrat les crueltats que narra des d'aquesta religió, no la diferencia gens de la cultura cristiana de l'època i, fins i tot, a la fi el protagonista tria Alger com la seua llar per sempre, tot sotmetent-se a un procés d'aculturació voluntari.

A Matinada de llops (Miralles 2005) també es critica la malfiança de la població, en aquest cas, contra els moriscos que encara queden a terres valencianes i que focalitzen els odis de tota la població. A la novel.la algú assassina Jaume Mateu quan se'n va cap a València a satisfer una sucosa multa reial. La desaparició dels diners podria 
XAvier Mínguez-López

La interculturalitat a la literatura infantil i juvenil catalana

sumir en la misèria la població i totes les sospiten cauen sobre Adil, un criat d'origen musulmà que l'acompanyava:

\footnotetext{
Infidel moro traïdor! Tu l'has mort i tu seràs condemnat a la terra i a l'infern, pels homes justos i per Déu, també pel teu Déu.[...]

Així has pagat que un home t'aixoplugara i et salvara de l'infortuni? D’aquesta manera agraeixes que t'acollira a sa casa i que et deixara compartir amb ell la calor de la llar i el pa per a menjar?

Bé, ja li ho déiem tots. No et refies d'aquesta gentola. (p. 15)
}

Sense necessitat d'anar tan lluny, a Quan tot comença (Pons i Clar 2006) també es reflecteix d'alguna manera una societat multicultural, en aquest cas la Mallorca dels seixanta. Encara que és absolutament predominant el punt de vista local focalitzat en el protagonista, un xiquet que aspira a ser pescador com son pare mort i que aprofita l'estiu per a eixir amb la barca, jugar amb els amics, i altres activitats tradicionals de l'època. Malgrat aquest paisatge general, cal reconéixer que s'hi fa referència als guàrdies civils immigrants espanyols ${ }^{2}$ que, a més a més, parlen en castellà a l'obra. La coprotagonista és nascuda a Argentina, filla de mallorquins que van haver d'emigrar per diferents raons, incloent-hi la Guerra Civil, amb la qual cosa trobem una forma diferent d'immigració, a mitges entre la recerca de les arrels, la tornada i una nova emigració.

A més d'anar-se'n al passat, també hi ha l'opció d'anar a un altre país per tal de mostrar la societat multicultural. És el cas d'Història d'amor a Sarajevo (Benavente 2005). Aquest llibre és un bon exemple de la globalització i els seus efectes arreu del món. La internacionalització de la guerra ve atribuïda a conflictes polítics entre països europeus i la salvació que hauria d'arribar d'Occident no arriba mai. En aquest marc internacional, la multiculturalitat és palesa en la complexa societat bosniana i hercegovina: jueus, catòlics, musulmans i també albanesos, serbis, croats, etc. El llibre és plenament intercultural perquè defensa la convivència pacífica entre les diferents ètnies amb un clam constant a l'essència dels éssers humans. La guerra iguala tots els personatges i els fa bàsicament persones. Creiem que es pot comprovar facilment que la convivència ha estat un fet durant la llarga història d'aquest poble:

S'escolta la paraula genocidi. Tots els serbis són iguals? Potser de fora estant ho creuen, però tant la Selma com el seu pare saben que no, almenys no l'escriptor que està parlant a la ràdio, ni tampoc en Marko Krulic, aquell vidu que s'ha negat a deixar Bascarsija. I n'hi ha més com ell, a la zona assetjada de la ciutat. També hi ha jueus, com l'Isaak Balzian, l'antic

2. Hem considerat els personatges de procedència castellana com a estrangers en llibres en què la seua presència resulta clarament aliena a la resta de personatges locals. 
restaurador de llibres a la destruïda biblioteca i bon amic del pare. Darrerament hi ha qui el mira amb recel, i a en Kemal li sap greu. Ah, el bon Isaak Balzian, enamorat de la seva ciutat i de la seva professió amb els llibres. I ara s'ha de sentir vigilat per alguns dels seu veïns. És culpa dels «internacionalistes àrabs» que estan emmetzinant la ment de molta gent. Tant se val que la comunitat hebrea de la ciutat sigui de les més actives a l'hora d'ajudar els refugiats i necessitats, jueus o no, i que el mateix Estat israelià s'hagi ofert per ajudar els sarajevians [...] (p. 20)

De tota manera, malgrat l'intent de l'autor de mantenir-se imparcial, a la fi la crueltat dels soldats serbis acaba per dur el lector de part de Selma i Petar. Paradoxalment, aquesta és una parella prohibida, a la manera de Romeu i Julieta i d'altres, ja que ella és bosniana i ell serbi. La seua relació sota les bombes i els franctiradors esdevé una metàfora de l'amor que supera les barreres i s'imposa a les circumstàncies siguen quines siguen.

El cas d'El desert de gel (Carranza 2006) resulta una mica més complex perquè mostra sens dubte una societat multicultural de diferents maneres. D'una banda, les bruixes protagonistes són internacionals i s'agrupen en clans que no corresponen necessàriament amb nacionalitats; així, les reunions de bruixes són multiculturals. De l'altra banda, els clans enfrontats són realment dues cultures enfrontades que a la fi arriben a un cert acord per tal de protegir la filla d'un amor mixt. Finalment, la major part de la trama es concentra a l'estranger, en un llarg viatge cap al nord d'Europa que durà els protagonistes a Islàndia i on entraran en contacte amb altres realitats. El cas és que Selene és catalana, encara que no fa referència especialment a la seua nacionalitat. Tan sols en fa referència en contrast amb l'aparença clarament nòrdica de Gunnar.

Aquestes formes de societat multicultural, però, presenten problemes si analitzem el missatge que llancen al lector, sovint contradictori amb les intencions primeres. Les mostres de multiculturalitat poques vegades es tradueixen en interculturalitat i l'aparició de les altres cultures comporta de vegades un rebuig implícit. És el cas del primer llibre que esmentàvem, Anem, Gruny (Ginesta 2002), on aquesta diversitat que es mostra resulta sempre negativa, ja que la xiqueta rebutja el contacte amb els personatges de rondalla que, a més a més, són tots dolents en els seus papers tradicionals.

El mosaic de què parlàvem a Terramolsa (García Llorca 2004) és un mosaic de criatures allunyades de la civilització i de les normes socials convencionals. Aquests outsiders mantenen les seues marques d'identitat més com a defensa que com una voluntat de transcendir les diferències amb els altres. També són outsiders els diferents personatges que fan la seua aparició a La mala bèstia (Garcia Llorca 2003) i que quasi la majoria tenen una fi tràgica, com els gitanos o el francesos.

En altres casos, la multiculturalitat és tutelada, com si tota aquesta diversitat necessitara un cap visible, algú que poguera posar trellat en el desgavell que suposa la 
XAvier Mínguez-López

La interculturalitat a la literatura infantil i juvenil catalana

convivència entre cultures. El narratari de Nas de barraca (Desclot 2004) envia el seu nas a investigar al seu hort, ni tan sols ho fa ell mateix, i emet diversos judicis sobre com procedeixen els insectes del circ. L'altre personatge humà, malgrat que rep un regal preciós, com és una cançó composta i escrita pels animals del circ, no pot evitar exercir l'autoritat que li atorga ser humà i els demana de canviar la lletra:

Però en Bieló els va fer callar amb un gest i els va dir:

—Lúnica cosa que potser es podria millorar són les lletres. No trobeu?

Els artistes es van mirar ells amb ells, bocabadats, perquè es pensaven que les lletres eren el millor de la collita de la vespa Xana.

—No t'han agradat? — va gosar demanar, desinflada, la marieta Delullviu.

—No és que no estiguin bé. Són prou divertides, però són una mica desgavellades. No trobeu?

Ells no ho trobaven, però ara que els ho deia en Bieló ja començaven a dubtar.

—Potser sí, doncs — va fer l'aranya Delacreu, que tenia una mica més de seny que els altres.

- Podem fer un pacte — hi va afegir en Bieló -

—Quin pacte? — van demanar tots, desconcertats (i mai tan ben dit).

—A partir d'ara, jo us escriure les lletres i vosaltres hi posareu la música. Què us en sembla?

—Fantàstic! — va cridar la Reina, que no podia sofrir haver de cantar les lletres d'una vespa. (p. 86)

Aquesta figura que està per damunt del melting pot també apareix en Aristòtil entre escombraries on, després de fer una passejada per la varietat d'escombraries que hi ha a l'abocador (cadascú amb la seua història i personalitat) el personatge no s'està de fer una recomanació des de la seua postura de savi d'altre temps:

—Doncs, saps què, Follet? A mesura que us anava sentint, un rere l'altre, jo anava trobant que aquesta vida que porteu aquí no sembla pas de Paradís, sinó més aviat de Purgatori.

—Què vols dir, amb això?

-Que jubilar-se com a deixalla no és cap meravella.

—Què vols dir, què vols dir? — s'atabalava el pobre Follet- Ja no ens trobes una meravella? Tan feliços que vivíem!

-Us trobo fantàstics, ho pots ben creure, però em sembla que us conformeu amb massa poc.

-Què vols dir, què vols dir, què vols dir?

—Què hauríeu d'aprendre a tornar.

-M'he perdut, Aristòtil. No sé pas on vols anar a parar.

- Vull dir que hauríeu d'aspirar a renéixer. En aquesta terra, em penso que ja t'ho dit abans, tot el que mor reneix: la fulla seca es torna aliment d'arbres nous, l'ovella morta es converteix en carn de llop o de voltor, tot es regenera. (pp. 30-3I)

També el president de França està per damunt del massai africà a L'escola secreta de Madame Dudú i hi actua amb un declarat paternalisme quan decideix donar-li ajuda, malgrat que es permet també fer judicis de valor sobre les seues decisions que, a més, considera equivocades: 

mantenir?

—Per què volen tres criatures de París, a l'Àfrica, si ells en tenen més de les que poden

El president estigué d'acord que Ben-Bow era un somiatruites i que els somiatruites són així: les quimeres formen part de la seva personalitat. Tanmateix, havia confiat en ell amb la candidesa d'un infant o d'una ànima molt pura i no el pensava decebre. (p. 59)

És clar que, en aquest cas, el paternalisme s’aplica en tant que el blanc és una persona assenyada i el negre, el diferent, l'altre, és una ànima pura que necessita de l'ajuda d'Occident.

Tampoc no està exempta de problemes la imatge d'altres societats multiculturals representades de manera simbòlica, és a dir, situades en altres paràmetres espaciotemporals. Com déiem a El darrer manuscrit, la convivència és forçada i no convenç cap dels pobles implicats. Ací ens trobem amb una nova paradoxa en l'anàlisi des del punt de vista intercultural. És obvi que el contacte de cultures provoca conflictes els quals es consideren positius des d'un punt de vista no violent, perquè permeten iniciar el diàleg i resoldre pacíficament els conflictes. Però també és cert que la presentació del contacte de cultures de manera inevitablement conflictiva ens transmet una visió negativa que s'associa sovint amb enfrontaments, desacords i, fins i tot, agressions. La representació de la multiculturalitat com un mosaic pacífic, si bé en promou la visió positiva, també amaga els possibles conflictes que puguen generar les diferents visions de la societat que les cultures posseeixen. Sens dubte, cal tenir en compte dues qüestions: com tracta l'autor o l'autora tant una postura com l'altra i com es treballa des de l'àmbit educatiu els diferents punts de vista mostrats. És a dir, més que en les obres, sovint cal pensar en la lectura de les obres.

Si apliquem aquest enfocament a una altra obra com és Animals!, veiem que el missatge general que vol transmetre aquest llibre respecte de la globalització, la colonització i la convivència és molt engrescador. Tanmateix, l'autora situa els africans en un estadi primitiu que identifica amb l'arrelament a la natura amb bona cosa de tòpics: un cap de tribu egòlatra o la necessitat d'un bruixot per a determinades tasques, per citar-ne dos exemples. S'hi dóna una visió d'Àfrica i dels seus habitants altament estereotipada, sense ciutats, serveis sanitaris, democràcia, etc.; de fet, s'sassimila directament l'estatus d'aquesta tribu amb la dels animals amb els quals s'alia per tal de fer fora els humans blancs:

—Escolta'm bé, tros d'estora — va dir estirant-li la cua per evitar que l'altre fugira covardament-Quan els animals van abandonar les seues terres, la tribu també la va haver de deixar. El lleó començà a entreveure la llum:

- Per tots els trons del cel! Aquestes terres sempre han pertangut a la tribu —De sobte, va callar, cavil.lós_ - Per què no s'han deixat veure? Per què no han vingut a reclamar el que és seu? (p. 104) 
XAVIER MíngueZ-López

La interculturalitat a la literatura infantil i juvenil catalana

A més d'aquestes contradiccions o, si més no, paradoxes en la representació de les societats multiculturals també ens trobem amb una altra paradoxa: la representació de la nostra societat actual multicultural és pràcticament absent dels llibres estudiats. La multiculturalitat es prefereix lluny i se situa al passat, al futur o a l'estranger.

L'apel.lació al nostre passat multiètnic, d'una banda, vol despertar la consciència del fet que nosaltres també vam viure, en la nostra història, aquesta situació que ara sembla nova. Però, de l'altra, no deixa de fer l'efecte que la composició multiètnica de la societat és una cosa del passat i que a hores d'ara ens enfrontem amb una societat cohesionada al voltant de les idees nacionals, amb la incorporació d'altres pobles i cultures que, abans o després, s'hauran d'integrar. Així, sense negar l'aportació a una educació intercultural d'aquestes obres, també cal reconéixer que obrin altres interrogants al voltant de quines reflexions cal fer sobre la nostra història llunyana i recent.

\subsection{L'ABSÈNCIA DE LA SOCIETAT MULTICULTURAL}

Però si la manera de presentar la societat multicultural fa pensar, la seua completa absència creiem que és realment preocupant. El 60\% dels llibres no la fa palesa de cap de les maneres, cosa que transmet, inevitablement, la sensació d'una societat monolítica i una visió de la cultura estàtica. ${ }^{3}$ Entre els llibres que presenten aquesta mancança creiem que podem distingir dues tendències: les obres que presenten un món molt poc marcat culturalment encara que, per defecte, el lector les adscriuria a l'estàndard, i les que mostren la nostra societat tot obviant la presència de diferents cultures.

Entre les primeres, trobem moltes obres per a primers lectors en les quals les referències culturals són bastant escasses. A Ziu, lleva't (Ginesta 2004) el gos protagonista no mostra cap signe de multiculturalitat perquè en realitat tan sols du a terme les tasques d'higiene diària a casa seua. Tot i així, gràcies a la il·lustració, es pot apreciar en la manera de vestir, els mobles i complements que s'encabeix sense problemes en la nostra cultura. A El ninot de neu (Pedroso \& Peiró 2004) l'absència de personatges humans no permet la inclusió d'aquesta riquesa cultural que si bé s'expressa en menor mesura per l'abundància d'animals que fan costat al ninot, no acaba de suggerir una societat mosaic, sinó un personatge central amb comparses que li permeten expressar-se.

Tampoc a Menú d'astronauta (Desclot \& Farré 2003) el text succint i les il.lustracions que narren una història al marge del poema no deixen massa lloc a la

3. Incloem ací alguns llibres on apareix un personatge estranger perquè, sovint, aquesta circumstància és anecdòtica i no suggereix la presència de la societat multicultural. 
presentació d'una societat multicultural. Els autors resolen la tasca amb fórmules senzilles que ni inclouen ni exclouen aquesta presentació. Un cas semblant és el dels altres llibres de poemes com Disfresses (Sala Valldaura \& Julià 2002) o Les petites (i grans) emocions de la vida (Gisbert 2003). Les referències, els marcs espacials, els personatges que es fan servir, etc. no introdueixen elements multiculturals, en part per les seues característiques (són llibres de poesia). Això no vol dir, de cap manera, que no podrien incloure-les. N'hi hauria prou amb fer un ús més conscient de les il.lustracions — com a El nen que feia pondre el sol (Pastor \& Canals 2005) o El nen gris (Farré Estrada \& Gusti 2006) — o amb incloure algunes referències a la multiculturalitat.

De manera semblant, el món pintat a El mur i el dragó (Prats \& Fanlo 2005) i a Vull una corona (Portell \& Blanch 2005) evita la representació de la societat multicultural; no sabem si amb major nombre de personatges i situacions sorgiria de forma natural o no. En el segon cas, però, l'ill-lustrador es recrea en motius clarament al-lusius a una manera de veure el món molt lligada amb la nostra cultura i les nostres referències. L'exemple més palés el podem veure en aquesta il.lustració dels guàrdies dels palaus que exhibeixen uniformes d'inspiració prussiana, malgrat que la resta de personatges vesteixen de manera més actual.

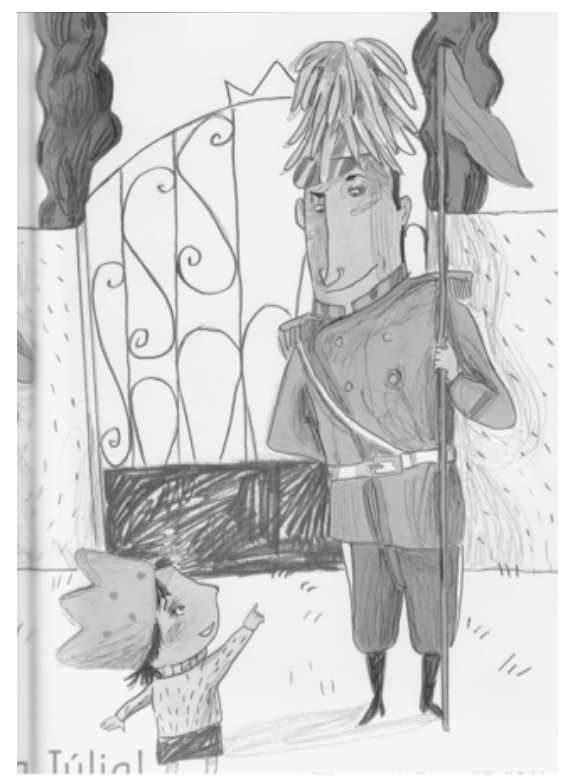

Vull una corona. 
Xavier Mínguez-López

La interculturalitat a la literatura infantil i juvenil catalana

En aquesta frontera se situen també llibres com El mar de la tranquil.litat (Sampere \& Alcobre 2004), en el qual la recreació de l'interior de la ment del xiquet en coma no facilita la representació d'aspectes multiculturals tot i que, en cas que l'autor haguera volgut incloure-hi alguna referència, la trama hi deixava espai. Volem que tornin les vaques boges (Arbat 2004) o L'herència (Cela \& Tubau 2005) serien uns altres exemples en els quals els interessos dels autors no incloïen aquestes qüestions. A llibres com La ciutat dels ignorants (Arbat 2003), en canvi, allò que es planteja és una nova paradoxa. Si es vol representar una societat uniforme i monolítica, la inclusió de personatges marcats culturalment no trencaria amb aquesta intenció primera? La diversitat cultural — racial en aquest cas, que seria el més senzill de representar a través de la il.lustració- potser aniria en contra de l'objectiu de l'autor, a pesar que altres elements externs, com els uniformes, els habitatges o els treballs, ja fan la faena de mostrar aquest monolitisme del qual parlem. En aquesta il.lustració, per exemple, la inclusió de personatges de color no haguera desvirtuat gens la sensació d'uniformitat.

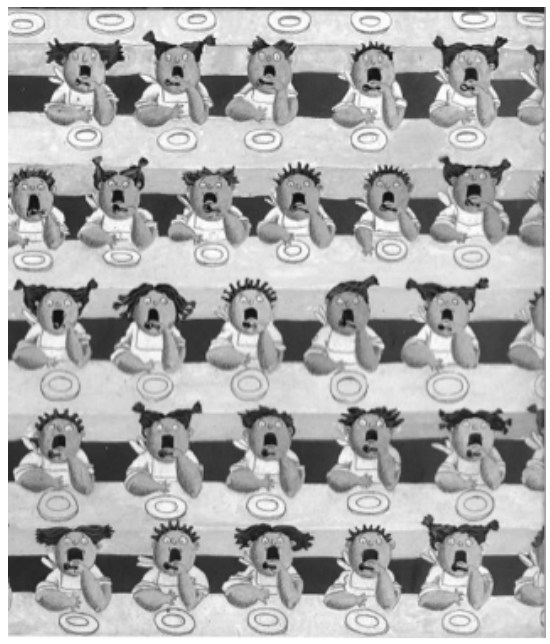

La ciutat dels ignorants.

Podríem completar aquests exemples de frontera en els quals la intenció del'autor podria haver fet més multicultural el llibre amb El capità i el gos orgullós (Bertran \& Miquel 2005), Unsac ple d'estrelles (Biosca \& Taurà 2003) o L'ovella Paquita (Farré 2005). Com diem, no s'hi troba a faltar pel fet de parlar de gossos, d'ovelles o mostrar una història molt senzilla, encara que es podria haver enriquit l'obra. Aquests casos, però, són molt diferents dels llibres on es presenta la nostra societat actual i qualsevol rastre 
de diversitat cultural és esborrat del mapa. Parlem d'una gran quantitat d'obres que ignoren la composició de la nostra societat tot mostrant els estàndards esperables o bé, fins i tot, presentant un element divergent en un context absolutament monocultural.

A les obres ambientades al món rural és comú que els autors tracten de transmetre els costums, les tradicions i els hàbits de la nostra cultura més tradicional. Així, un llibre com Les costures del món (Broseta \& Boscà 2004), en el qual irrompen els personatges fantàstics dels quasis per tal de buscar les agulles d'or que els ajuden a protegir el seu món, ens permet reflexionar sobre el perill de desaparició d'aquests éssers amenaçats per l'avarícia dels joiers, que havien de fer-se càrrec de les agulles. En resum, el món està en perill i seran uns valencians els encarregats de salvar-lo. Curiosament, els xiquets se'n van a menjar la mona i a envolar la milotxa tot recuperant tradicions que, en determinats contextos, estan en perill de desaparició com els mateixos quasis. D'altra banda, els xiquets acudeixen a la seua àvia per tal de demanar ajuda, ja que aquesta — com a guardiana de les essències i de la saviesa que són totes les persones grans que viuen soles- és una gran cosidora i els pot ajudar a dur a terme aquesta tasca. Excusem dir que cap personatge, llevat dels quasis, té nom estranger o prové d'una cultura diferent.

És el mateix cas de l'obra Operació Tarrubi (Broseta \& Infante 2002), de la mateixa autora amb un plantejament similar: una criatura d'un món paral.lel necessita ajuda dels humans. Aquest personatge que és tractat amb paternalisme per part del xiquet protagonista, és l'únic element dissonant en una atmosfera perfectament estàndard $\mathrm{i} a \mathrm{mb}$ una absència cridanera de personatges estrangers o representants d'altres subcultures socials.

A vegades, focalitzar en aspectes de la nostra cultura porta a obviar aquesta qüestió com a Jo Tirant, tu Carmesina (Lluch \& Cabo 2006), on els personatges juguen amb les descobertes al voltant del llibre de Joanot Martorell. Novament hi trobem una gran uniformitat en els personatges: classe mitjana, blancs i valencians. També a La taverna del bandoler (Bö̈gues \& Gordillo 2006), la recerca estiuenca per part de Laura del collar de l'emperadriu no deixa lloc als estrangers; Ximo, Nati, Lídia, Jaume, Sílvia... són alguns dels noms que acompanyaran la protagonista en aquesta aventura que es du a terme en un poble valencià amb festes patronals, piscina d'estiu, iaios que conten històries als xiquets, etc. I parlant de bandolers, també la Catalunya del Xvir sembla culturalment homogènia segons la visió que es presenta a A carn, a carn! (Pradas 2002), la qual recupera la forma de vida dels bandolers i es fan nombroses referències a la cultura catalana de l'època. La part de la història que succeeix a l'actualitat tan sols serveix perquè el protagonista comprove les seues arrels històriques, la seua ascendència amb pedigrí.

Caplletra 61 (Tardor, 2016), pp. 61-89 
Xavier Mínguez-López

La interculturalitat a la literatura infantil i juvenil catalana

Una cosa semblant ocorre a El Justícia (Torró 2003). Encara que la descripció detallada de la València del xv sí que dóna compte d'una certa diversitat en la composició dels barris o dels oficis, també és cert que l'autor no s'hi recrea, ja que prefereix fer èmfasi en els personatges rellevants per a la cultura de l'època i no deixa de fer-se referència a Ausiàs March, Joanot Martorell o Jaume Roig. Creiem que El cementiri del capità Nemo (Rayó \& Auladell 2004) es podria incloure en aquest grup d'obres preocupades per mostrar determinades formes de vida i costums ja desapareguts. El detall amb què l'autor narra el dia a dia de padrí i nét sembla no deixar lloc a d'altres consideracions culturals encara que, com hem defensat més amunt, tota societat és multicultural d'una manera o altra.

Altres obres com Paper de diari (Martí \& Vila 2004), L’home del sac (Jové \& Tha 2006), Sóc molt Maria (Anguera \& Piérola 2002) o Els patins del Sebastià (Prats $\&$ Rovira 2003), se centren en el problema del xiquet i eludeixen les referències a la diversitat $i$, fins $i$ tot, es recreen en estampes poc comunes avui dia com aquesta barberia tradicional d'Els patins del Sebastià o aquest muntatge amb joguets artesans de Sóc molt Maria.

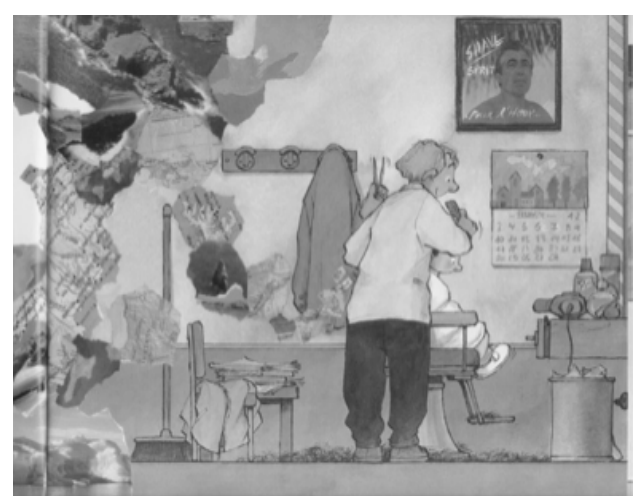

Elspatins del Sebastià.

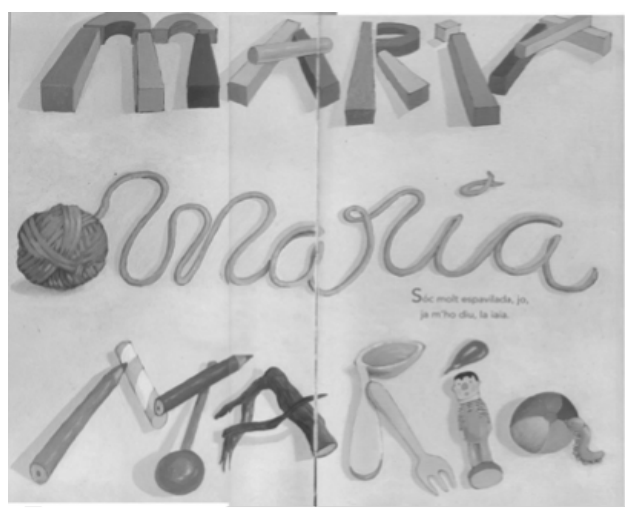

Sóc molt Maria.

Els darrers llibres esmentats són àlbums que, com dèiem, tot fent un ús intel.ligent dels personatges secundaris, podrien incorporar al-lusions a la societat multicultural, encara que prefereixen tendir més cap als aspectes tradicionals.

Des d'una altra perspectiva, tenim un grup de llibres que, malgrat fer menció o parlar amb certa profunditat d'un segment socialment marcat o d'un personatge estranger, ho fan des d'una visió de la societat del tot monocolor. És el cas d'A l'altra banda del mirall (Sierra i Fabra 2008) on, tot i tractar el despertar de la identitat sexual 
de la protagonista lesbiana, es desenvolupa en una Barcelona absent d'estrangers i, fins $\mathrm{i}$ tot, d'altres homosexuals masculins o femenins, llevat de l'amiga de la protagonista. Tant l'entorn immediat de Maria, com els llocs on acudeix (una torre a Sant Joan) resulten propis del seu grup social, sense cap aspecte que denote el fet de viure en una ciutat cosmopolita.

A Un petó de mandarina (Canal \& Ruano 2006) succeeix una cosa pareguda, ja que l'única estrangera que hi apareix és la coprotagonista, molt marcada com a estrangera, encara que no se'ns diu de quina procedència és. El seu nom, Vanina, bé podria ser italià, hebreu o àrab, encara que se suposa que és més aviat d'origen musulmà perquè el seu pare es diu Yussef. Tot i així, no coneixem res dels costums, les tradicions o les possibles distàncies culturals de la xiqueta, que no mostra cap diferència amb els seus companys, ni tan sols un accent diferent. La il.lustració tampoc no ajuda a diferenciar-la de la resta de personatges autòctons.

Finalment, cal esmentar els casos, si més no curiosos, en què es desenvolupa la història en un país estranger o en un lloc fantàstic i es mostra aquesta cultura com a també monolítica. En el cas de Iosa i les grues (Rayó \& Gubianas 2006) potser no hi ha espai per a la multiculturalitat, ja que el pas del poeta Bashoo per una aldea del Japó deixa poc d'espai per a altres consideracions. En el cas d'Els caçadors del sol (Oliver 2005) es recrea una societat completament fictícia i és difícil dissociar els elements que comportarien aquesta riquesa cultural dels que són inherents a la cultura dels protagonistes. En tot cas, no deixa de resultar curiosa la circumstància de presentar llibres multiculturals sense diversitat multicultural.

\subsection{ALTRES FORMES DE PRESÈNCIA DE LA MULTICULTURALITAT}

A més de les formes ressenyades anteriorment, la qüestió dels personatges, vam triar unes altres formes possibles de presència de la multiculturalitat i la interculturalitat en el nostre corpus. Una possibilitat era que hi haguera narracions sobre comunitats d'estrangers en un país europeu. Hem de dir que la presència d'aquestes obres al corpus és bastant residual. Tan sols hi trobem quatre exemples que podrien acomplir aquest requisit i d'aquestes, novament, tres són novel-la històrica - Un riu d'espigues, La història d'En Robert (Anguera 2005) i L'esclau del Mercadal — i tan sols una està ambientada a la nostra època, De Nador a Vic. L'interés per aquests col-lectius és, si no escàs, pràcticament inexistent, ja que l'autora d'aquest llibre és marroquina i narra la seua experiència. Així doncs, els immigrants que viuen a casa nostra no reben cap tractament per a la LIJ, però tampoc altres col-lectius que formen part de la nostra

Caplletra 61 (Tardor, 2016), pp. 61-89 
Xavier Mínguez-López

La interculturalitat a la literatura infantil i juvenil catalana

societat des de temps immemorial. Pensem en aquest cas en els gitanos, que tan sols fan una breu aparició a La mala bèstia com a contrabandistes que viuen a la muntanya (i que són morts per mostrar desconfiança davant del protagonista). Per a la resta, el poble gitano és absolutament invisible, fins i tot en les formes estereotipades.

Aquesta invisibilitat és escandalosa si pensem en el pes demogràfic d'aquest poble als territoris de parla catalana (IIo.0oo persones aproximadament), però també ho és si pensem en la seua influència cultural. Una influència que, a més del lèxic que ha proporcionat a la nostra llengua, també s'estén a altres terrenys, en especial la música. Malgrat aquestes obvietats, la seua presència en la nostra LIJ és quasi nul.la tant de manera explícita com de manera implícita. Els gitanos continuen sent els grans damnificats d'una multiculturalitat que obvia el grup ètnic més antic que forma part de la nostra societat. Darrere de la seua absència veiem una interculturalitat que prefereix enfrontar-se amb els reptes que vénen de l'estranger abans que mirar a la pròpia diversitat. És possible que el desconeixement de la realitat del poble gitano també siga un handicap per als autors i autores a l'hora de retratar personatges d'aquesta ètnia. En tot cas, no deixa de ser una assignatura pendent.

Els autors i les autores de LIJ mostren més interés pels relats sobre una cultura estrangera, els quals suposen una quarta part del nostre corpus, tant quan aquesta cultura estrangera s'entén de manera literal, com quan s'entén de manera figurada en el cas de la visita d'éssers d'una altra dimensió, que viuen a les clavegueres o dins de la terra. Com ja hem comentat, no són literatura multicultural en sentit estricte del terme, però poden servir per introduir la visió de noves formes de vida als infants $\mathrm{i}$ joves. Llegint Operació Tarrubi no resulta gens complicat preguntar-se com seria la nostra vida si haguérem de viure a les clavegueres amagant-nos de les persones. També pot tenir la seua rendibilitat des de l'educació intercultural preguntar què hauríem de canviar de les nostres rutines si fórem gats i haguérem d'adoptar un parell de ratolins, com succeeix a L'herència.

En la major part dels altres casos, relats sobre una cultura estrangera real, trobem el personatge autòcton que anomenàvem anteriorment que ens fa de cicerone per la terra que s'explora, bé siga el nord d'Àfrica, Islàndia, Ucraïna o bé Còrdova. Tan sols una part menuda d'aquestes obres s'arrisca a endinsar-se per complet en el bany intercultural que suposa introduir-se en una altra cultura i escriure el llibre des de la seua perspectiva. Tot i així, cal reconéixer que tots els autors i les autores fan unes obres molt reeixides que aconsegueixen la identificació amb les cultures reflectides. La passejada lírica pel Japó de Miquel Rayó a Iosa i les grues, l’angoixosa experiència de la guerra narrada per Jaume Benavente a Història d'amor a Sarajevo, el fascinant món del París del segle XIx de La Torre de Vicenç Villatoro, la immersió absoluta en 
una comunitat indígena que fa Maria Àngels Bogunyà a Les veus protectores (2004) o, des d'una altra perspectiva, el viatge a París per part de Rosa Maria Colom Roca a L'escola secreta de Madame Dudú són exponents de l'atenció, encara escassa, que els autors i les autores de parla catalana dediquen a unes altres cultures. En les primeres quatre obres, l'equilibri entre el component forà i la trama s'aconsegueix d'una forma magnífica i el lector no estranya el fet que l'autor siga un outsider.

Molta menys presència tenen els relats sobre grups socialment marcats com puguen ser els homosexuals, la gent gran o les dones com a col-lectiu. En aquest cas, hem de parlar d'una presència realment minsa d'obres d'aquestes característiques. Només dos llibres tracten de l'homosexualitat - A l'altra banda del mirall i Sense cobertura (Garcia i Cornellà 2002). A més a més, d'aquests dos llibres, un tria aquesta temàtica com a eix central i absolut de la història, de manera que els temes secundaris emfasitzen la normalitat de la protagonista. La normalitat de l'entorn, i la corresponent anormalitat de l'homosexualitat, comporta que es narre la descoberta de la seua identitat sexual com una epifania en lloc de com un procés. De fet, necessita l'ajuda d'un altre personatge per tal d'assumir-la, com si en lloc del lesbianisme, haguera d'assumir un càncer de pulmó:

Va fer el gest d'aixecar-se, però la Fontsanta ho va impedir. Va retenir-la al seu costat agafant-la per la mà. La seva fermesa i la seva mirada, ara piadosa, a més de forta, van fer la resta.

-Fontsanta, sisplau...

-Digue-ho.

- ¿Que digui què?

-Ets lesbiana.

La paraula va esclatar allà al mig, entre les dues, silenciosa però alhora tan contundent com qualsevol dels petards disparats durant la nit [de Sant Joan]

- ¿Què?

—Ets lesbiana — va repetir la Fontsanta. Has lluitat contra això, contra la veritat del teu cos i del teu cap, però no has pogut, perquè l'amor, els sentiments, la pròpia realitat de l'essència humana, no s'imposen, només es manifesten.

— ¿T’has tornat boja? — va gemegar defallida.

—Et faré costat — va adreçar-li un somriure tan malenconiós com orgullós. La societat ens marca, ens imposa regles, ens diu el que està bé i el que està malament, però cadascú és com és, i com més aviat ho descobrim millor, és molt millor per afrontar-ho i actuar en conseqüència. Ja hi ha llibertat, ja es pot ser el que un és, però encara és dur perquè els altres tendeixen a marginar-te. Per això a l'adolescència, en el moment de descobrir aquesta veritat, per a la majoria és com descobrir que no hi ha terra sota els peus i que al cap un forat negre ens xucla.

-Però jo no...

—Maria — va pressionar-li la mà que seguia retenint entre les seves. Ho vaig saber des del primer moment, així que et vaig veure. Per als altres eres una noia normal i corrent. Per a mi no. Tinc un sisè sentit, i et vaig reconèixer. Tot el que desprens, el que destil.les. És un segell invisible, excepte per a algú com jo.

- ¿Tu ets...?

—Ho sóc —va assentir ella. (pp. I40-I4I) 
Xavier Mínguez-López

La interculturalitat a la literatura infantil i juvenil catalana

Aquest llibre parla del despertar de la identitat lèsbica de la protagonista, cosa que hauria d'ajudar a incloure'l en una qualificació de multicultural, però ho fa des d'una perspectiva tan heterocèntrica que aquest despertar es viu com si la identitat sexual no fóra una faceta pròpia de l'ésser humà. No resulta creïble que la protagonista, amb I6 anys llargs no haja fet cap reflexió sobre la seua condició de lesbiana fins que una altra lesbiana li ho fa saber, li ho comunica com si li haguera fet un diagnòstic. D'altra banda, com ja hem dit, la resta del llibre no mostra cap altra mostra de diversitat: no hi apareixen personatges obertament homosexuals, ni d'altres ètnies ni nacionalitats.

Trobem que el tractament que se li dóna a Sense cobertura fa més justícia als dubtes sobre la identitat sexual per diverses raons. D'una banda, la sexual no és l'única diversitat que s'hi mostra, ja que també hi trobem una família peculiar amb el pare fugit i el germà ocupa. D'una altra banda, el personatge afirma des d'un bon principi que no dubta de la seua identitat sexual, sinó de com fer-la patent, com assumir-la per complet, cosa que equival, bàsicament, a fer-la pública. Ningú no li ha de dir quina és la seua identitat, ha de conviure amb ella. A més a més, encara que el tema de l'homosexualitat és el que travessa tota la novel.la, el protagonista no deixa de tenir altres vivències que complementen els seus pensaments al voltant de la seua identitat sexual.

Un altre grup social que fa una discreta aparició en el nostre corpus és el de la gent gran, al qual estan dedicats en part Jo, el desconegut (Dalmases 2005), La història d'En Robert i El cementiri del capità Nemo. Tots tres parteixen del personatge juvenil o infantil, però fan un retrat bastant aproximat de la vida quotidiana, els pensaments i les preocupacions de la gent gran. Sens dubte, de tots tres, el que millor descriu aquesta etapa de la vida, encara que en un estadi bastant penós com és patir Alzheimer, és Jo, el desconegut. A més a més, aquesta malaltia està lligada d'una manera molt intel.ligent amb el que serà la trama principal, com regirar en el passat de l'avi per tal de saber sobre la fi del seu germà, membre d'un comando dels maquis. El fet que Arnau entre a formar part de la vida de Ramon a través d'una associació de suport als ancians reforça la idea que cal un major coneixement d'aquest col-lectiu.

La multiculturalitat ací es reflecteix en la ignorància per part de la societat d'aquests vells que funcionen com una comunitat autònoma amb el seu sistema de valors desconnectat $i$, quasi en diríem, inservible per als temps moderns. Aquest xoc acaba amb la comprensió profunda de l'altre i el compromís irrenunciable de la part dominant, els joves, quan entren en contacte i comprenen els valors de la part dominada, els grans.

Als altres dos llibres el coneixement dels majors es fa d'una manera més indirecta, a través de la convivència dels néts. En tots dos casos es reforça molt la idea dels avis 
com a contenidors de saviesa i de coneixements que, en alguns casos, corren el risc de perdre's si no hi ha una transmissió que, sovint, és menyspreada pels més joves.

Si aquests dos col-lectius estan poc tractats en el nostre corpus, les dones com a col.lectiu, o la mirada femenina, està completament fora del nostre corpus. Hi ha molt poques protagonistes femenines, de manera que era previsible que les dones tingueren una representació més aviat escassa en el nostre corpus. En tot cas, podríem citar algunes obres que, tot i focalitzar en altres qüestions, sí que transmeten un cert interés pel punt de vista femení, amb totes les prevencions necessàries sobre allò que significa la feminitat. Així Sóc molt Maria, Vols ser el nòvio de la meua germana? (Carranza 2002), Kor de parallamps, A l'altra banda del mirall, Les veus protectores, De Nador a Vic, Història d'amor a Sarajevo, L'infern de Marta (Alapont \& Garrido 2003), Aiguablava (Mollà \& Bosch 2006) i, especialment, El desert de gel, transmeten aquesta mirada, esguitada sovint de reflexions de les protagonistes al voltant de la seua condició de dones. Una de les qüestions més recurrents és el tema de la independència, sobretot en contrast amb els homes, i la veiem no tan sols en una obra on aquest tema té una especial rellevància per l'origen de la protagonista com és De Nador a Vic, sinó també en d'altres més innocents com Aiguablava o Kor de parallamps. També hi ha reflexions al voltant de la indefensió davant les agressions de gènere a Les veus protectores, Història d'amor a Sarajevo o, òbviament, L'infern de Marta on en són l'eix central.

De tota manera, malgrat l'esforç d'aquests llibres per reflexionar al voltant del món de les dones, no hi ha cap llibre al corpus que adopte aquesta perspectiva plenament.

\section{CONCLUSIONS}

Així doncs, podem parlar d'interculturalitat en una gran majoria d'obres si partim dels pressupòsits que hem expressat al marc teòric. Més del 60\% dels llibres, doncs, mostren d'una manera o altra aquesta interculturalitat entesa des d'un punt de vista més aviat ampli. En el nostre cas, parlem de les lectures interculturals, com proposa en primer terme Ming-Shui Cai (2002), que permeten llegir els llibres en termes de les implicacions culturals o les diferències que sorgeixen durant la seua lectura. És aquesta lectura de tipus ideològic la que ens permet detectar aquest nivell tan alt d'interculturalitat a les obres, ja que la interculturalitat en la seua expressió de contacte entre diferents cultures (enteses també de manera àmplia) es dóna en menor mesura. A la LIJ catalana sembla que no existeix un gran interés per tractar temes de caràcter intercultural que en altres països amb una composició més diversa són molt habituals. 
XAvier Mínguez-López

La interculturalitat a la literatura infantil i juvenil catalana

La multiculturalitat, doncs, entesa com la convivència entre diverses cultures és bastant minoritària al nostre estudi. Parlaríem d'un $25 \%$ de llibres dels quals la majoria transcorren al passat, al futur o a l'estranger. Més que un cànon, seria un grup de lectures recomanades.

Trobem que, en resposta a la hipòtesi que preguntava sobre si la LIJ catalana és un fidel reflex de les nostres societats, cal cridar l'atenció sobre la falta de lligam entre totes dues. La nostra LIJ no és un fidel reflex de les nostres societats perquè obvia el component multicultural en tot el seu abast; la diversitat dels nostres carrers, les nostres aules i les nostres realitats, que són molt més diverses del que trobem als llibres.

Parlem en primer lloc de les narracions sobre comunitats d'estrangers en un país europeu. Els immigrants encara no tenen veu a les nostres obres com a col-lectiu (sí com a personatges) i aquestes novel-les no apareixen en el nostre corpus més que de manera simbòlica, amb l'excepció de l'obra citada De Nador a Vic.

Tampoc no són massa nombrosos, encara que n'hi haja un percentatge superior, els relats sobre una cultura estrangera, sobretot si, en lloc de fer servir un personatge autòcton com a protagonista i guia per aquest país, es decideix la identificació completa amb el país tot esborrant les dades que situen el llibre en l'àmbit de parla catalana. Aquests intents, però, solen ser més reeixits i, en certa manera, són més rendibles des de l'educació intercultural que l'altre cas en el qual sempre hi ha algun tipus de mediació.

En canvi, els grups socialment marcats (determinats col-lectius que reclamen la seua presència a la societat) queden molt malparats en aquest treball. Tan sols trobem dos llibres focalitzats de forma clara en els homosexuals i dos coprotagonitzats per gent gran. L'altre col-lectiu important, les dones (hi insistim, com a col.lectiu), no ha merescut cap llibre en concret, encara que els protagonismes femenins permeten fer algunes reflexions sobre el fet de pertànyer a aquest grup.

Les nostres hipòtesis, doncs, es confirmen: en la tensió entre allò local i allò global en la LIJ catalana, la balança sembla inclinar-se cap al primer punt. Si bé és cert que hi ha obres d'aquest període que busquen la multiculturalitat, són llibres publicats ad hoc i no han tingut un tractament especialment bo per part de la crítica, raó per la qual no apareixen al nostre corpus. El que ens interessava, de fet, era comprovar la presència d'aquest fenomen en un corpus d'obres estàndard, no en obres creades a propòsit per mostrar la multiculturalitat o la interculturalitat.

Considerem, doncs, que són molt més interessants les lectures interculturals (Mínguez 20I0) que permeten detectar, com hem tractat de fer en l'anàlisi del corpus, els biaixos culturals i faciliten la discussió al seu voltant. Si la interculturalitat, com hem dit, ha de plantejar més preguntes que respostes, aleshores el mètode ideal per a treballar-la a les aules és, certament, plantejar els mateixos dubtes que hem 
tingut nosaltres, dur l'alumnat de qualsevol nivell als mateixos atzucacs als quals hem arribat nosaltres i comprendre, finalment, que la interculturalitat és, bàsicament, una mirada al nostre interior.

\section{I TAUleS DE ClASSIFICACiÓ}

\section{I.I Llibres multiculturals}

\begin{tabular}{|l|l|}
\hline 1. Animals! & 2. Terramolsa \\
\hline 3. L'escola secreta de Madame Dudú & 4. Les veus protectores \\
\hline 5. El silenci del mariner & 6. L'esclau del Mercadal \\
\hline 7. Kor de parallamps & 8. De Nador a Vic \\
\hline 9. Al-Rhazes, el metge de la talaia & 10. Ens barregem \\
\hline 11. Gent de pedra & 12. El somni d'un cavallet de fusta \\
\hline 13. La mala bèstia & 14. El darrer manuscrit \\
\hline 15. Un riu d'espigues & 16. Història d'amor a Sarajevo \\
\hline 17. El misteri de les quatre punyalades & 18. Matinada de llops \\
\hline 19. A l'altra banda del mirall & 20. Sense cobertura \\
\hline 21. Jo, el desconegut & 22. Història d'En Robert \\
\hline 23. El manuscrit de les bèsties & 24. El mapa del tresor \\
\hline 25. Un petó de mandarina & 26. Quan tot comença \\
\hline
\end{tabular}

\section{I.2 Llibres interculturals}

\begin{tabular}{|l|l|}
\hline 1. $\quad$ El bon somni & 2. Els colors de la memòria \\
\hline 3. Operació Tarrubi & 4. L'esclau del Mercadal \\
\hline 5. Animals! & 6. De Nador a Vic \\
\hline 7. L'escola secreta de Madame Dudú & 8. Ens barregem \\
\hline 9. El silenci del mariner & 10. El mur i el dragó \\
\hline 11. Sense cobertura & 12. Vull una corona \\
\hline 13. Un haikú per a l'Alícia & 14. Volem que tornin les vaques boges \\
\hline 15. L'aposta & 16. El capità i el gos orgullós \\
\hline 17. Bon profit! Mic i Mica & 18. L'herència \\
\hline 19. Menú d'astronauta & 20. El somni d'un cavallet de fusta \\
\hline 21. Les petites (i grans) emocions de la vida & 22. Les costures del món \\
\hline 23. Al-Rhazes, el metge de la talaia & 24. Mei-Mei vol ser rei \\
\hline
\end{tabular}


XAvier Mínguez-López

La interculturalitat a la literatura infantil i juvenil catalana

\begin{tabular}{|l|l|}
\hline 25. Gent de pedra & 26. El darrer manuscrit \\
\hline 27. El rei dels senglars & 28. Un riu d'espigues \\
\hline 29. A l'altra banda del mirall & 30. Ferum de silenci \\
\hline 31. El justícia & 32. Història d'amor a Sarajevo \\
\hline 33. Els llops de la lluna roja & 34. Jo, el desconegut \\
\hline 35. La mala bèstia & 36. Jo Tirant, tu Carmesina \\
\hline 37. Nas de barraca & 38. Iosa i les grues \\
\hline 39. L'Andreu i el mirall de les ganyotes & 40. La meua família i altres monstres \\
\hline 41. El mapa del tresor & 42. Un petó de mandarina \\
\hline 43. Aristòtil entre escombraries & 44. Aiguablava \\
\hline 45. Terramolsa & 46. Els caçadors del sol \\
\hline 47. Les veus protectores & 48. El desert de gel \\
\hline 49. El silencis de Marc & 50. El tresor dels maquis \\
\hline 51. Història d'un cap tallat & 52. Quan tot comença \\
\hline 53. De Satanasset a Aletes de vellut & \multicolumn{2}{|l}{} \\
\cline { 2 - 2 } &
\end{tabular}

Xavier Mínguez-López Universitat de València xavier.minguez@uv.es

\section{REFERÈNCIES BIBLIOGRÀFIQUES}

Referències bibliogràfiques secundàries

Abdallah-Pretceille, M. (200I) La educación intercultural, Barcelona, Idea Books.

Abdallah-Pretceille, M. \& L. Porcher (1996) Education et communication interculturelle, París, Presses Universitaires de France.

Aguado, M. T. (2003) Pedagogía intercultural, Madrid, McGraw-Hill.

Ariño, A. (I997) Sociología de la cultura: la constitución simbólica de la sociedad, Barcelona, Ariel.

- (2002) «Cultura», dins J. Conill, Glosario para una sociedad intercultural, València, Bancaixa (pp. 22-24).

Banks, C. A. M. \& J. A. Banks (200I) Multicultural education: issues and perspectives, Boston, Allyn and Bacon.

BAnks, J. A. (1997) Educating citizens in a multicultural society, Nova York, Teachers College Press. 
Bartolomé, M. (2002) «Educar para una ciudadanía intercultural», dins M. Bartolomé, Identidad y ciudadania: un reto a la educación intercultural, Madrid, Narcea, pp. I3I-I6I.

Besalú, X. (2002) Diversidad cultural y educación, Madrid, Síntesis.

- (2007) Educar en sociedades pluriculturales, Barcelona, Wolters Kluwer.

B Lоoм, H. (1995) Elcànon occidental: els llibres il'escola de les edats, Barcelona, Columna.

Bourdieu, P. (I99I) «Le champ littéraire», Actes de la recherche en sciences sociales, 89, pp. 3-46.

Del Amo, J. M. (2003) «Literatura infantil y canon formativo en la educación infantil», dins A. G. Cano \& C. Pérez Valverde, Canon, literatura infantil y juvenil y otras literaturas, Conca, Universidad de Castilla-La Mancha, p. 894.

- (2003) Literatura infantil: claves para la formación de la competencia literaria, Màlaga, Aljibe.

Even-Zohar, I. (2005) «Polysystem Theory (Revised)», dins I. Even-Zohar, Papers in Culture Research, Tel Aviv, Porter Chair of Semiotics, [sense paginar].

Hernández, G. M. (2002) La modernitat globalitzada: anàlisi de l'entorn social, València, Tirant lo Blanch.

Hunt, P. (2003) «Exploding the Canon: Children's Literature and the Revolution in Criticism», dins G. Cano Vela \& C. Pérez Valverde, Canon, literatura infantily juvenil y otras literaturas, Conca, Universidad de Castilla-La Mancha, pp. 2I-30.

JimÉnez GÁmeZ, R. (2004) Inmigración, interculturalidad y curriculum, la educación en una sociedad multicultural, Sevilla, Mcep.

Kyмlicka, W. (1995) Multicultural Citizenship: A Liberal Theory of Minority Rights. [Traducció al castellà (1996) Ciudadanía multicultural: una teoría liberal de los derechos de las minorias, Barcelona, Paidós.]

Mc GiLlis, R. (2003) «What literature was: the canon become ploughshare», dins G. Cano Vela, G. \& C. Pérez Valverde, Canon, literatura infantily juvenily otras literaturas, Conca, Universidad de Castilla-La Mancha, pp. 3I-44.

Mínguez, X. (2013) Literatura infantil i juvenil catalana i interculturalitat, València, Universitat de València. [Tesi doctoral disponible en http://roderic.uv.es/handle/I0550/28449.]

- (20I0) «Interculturalidad, multiculturalidad o localismo: un modelo para la LIJ catalana», dins J. Herrera, M. Abril \& C. Perdomo, Estudios sobre didácticas de las lenguas y sus literaturas, Tenerife, Universidad de la Laguna, pp. 559-572. MorIn, E. (2OIO) ¿Hacia el abismo?: globalización en el siglo XXI, Barcelona, Paidós. Shavit, Z. (1986) Poetics of children's literature, Athens, The University of Georgia Press. 
XAvier Mínguez-López

La interculturalitat a la literatura infantil i juvenil catalana

Sullà, E. (1998) El canon literario, Madrid, Arco-Libros.

Tombinson, J. (1999) Globalization and culture. [Traducció al castellà (200I) Globalización y cultura, Mèxic, Oxford University.]

Referències bibliogràfiques primàries

Alapont, P. \& V. Garrido (2003) Linfern de Marta, Alzira, Bromera.

Anguera, M. (2005) La història d'en Robert, Barcelona, La Galera.

Anguera, M. \& M. Piérola (2002) Sóc molt Maria, Barcelona, La Galera.

ARbat, C. (2003) La ciutat dels ignorants, València, Brosquil.

- (2004) Volem que tornin les vaques boges!, València, Editilde.

Ballart, M. (2005) Un riu d'espigues, Alzira, Bromera.

Benavente, J. (2005) Història d'amor a Sarajevo, Barcelona, Columna.

Bertran, X. \& G. Miquel (2005) El capità i el gos orgullós, Alzira, Bromera.

Biosca, J. \& J. Taurà (2003) Un sac ple d'estrelles, Barcelona, Abadia de Montserrat.

BogunYÀ, M. À. (2004) Les veus protectores, Barcelona, Baula.

BoÏGues, L. \& X. Gordillo (2006) La taverna del bandoler, Picanya, Edicions del Bullent.

Bolta, M. J. \& À. Ruiz (2002) Animals!, Barcelona, La Galera.

Broseta, T. \& F. Boscà (2004) Les Costures del món, Barcelona, Bromera.

Broseta, T. \& F. Infante (2002) Operació tarrubi, Barcelona, Barcanova.

Burgàs, À. (2004) M. A. X., Barcelona, La Galera.

Canal, E. \& S. Ruano (2006) Un petó de mandarina, Barcelona, Barcanova.

Carranza, M. (2002) Vols ser el nòvio de la meva germana?, Barcelona, Edebé.

- (2006) El desert de gel, Barcelona, Edebé.

Cela, J. \& V. Tubau (2005) L'herència, Barcelona, Cruilla.

Colom, R. M. (2002) L'escola secreta de Madame Dudú, Barcelona, La Galera.

Dalmases, A. (2005) Jo, el desconegut, Barcelona, Cruilla.

Desclot, M. \& L. Farré (2003) Menú d'astronauta, Barcelona, Cruïlla.

Desclot, M. \& O. Galí (2004) Aristòtil entre escombraries, Barcelona, La Galera.

Desclot, M. \& L. Jover (2004) Nas de barraca, Barcelona, Cruilla.

Farré, L. (2005) L'ovella Paquita, Barcelona, Alfaguara / Grup Promotor.

FARré, L. \& Gusti (2006) El nen gris, Barcelona, La Galera.

GaLícia, M. (2005) El darrer manuscrit, Barcelona, La Galera.

García i Cornellà, D. (2002) Sense cobertura, Barcelona, La Galera. 
García i Cornellà, D. (2004) L'esclau del Mercadal, Alzira, Bromera.

Garcia Llorca, A. (2003) La Mala bèstia, Barcelona, Proa.

- (2004) Història d'un cap tallat, Barcelona, La Galera.

- (2004) Terramolsa, Barcelona, La Galera.

Ginesta, M. (2002) Anem, Gruny!, Barcelona, Barcanova.

- (2004) Ziu, lleva't, Barcelona, Publicacions de l'Abadia de Montserrat.

Gisbert, M. (2003) Les Petites (i grans) emocions de la vida, València, Tàndem.

Hernàndez, P. J. (2005) El misteri de les quatre punyalades, Barcelona, Columna.

Huertas, C. J. (2003) Gent de pedra, Barcelona, La Galera.

Jové, J. M. \& THA (2006) L’home del sac, Barcelona, La Galera.

JuAnolo (2006) Ens barregem!, València, Tàndem.

Karrouch, L. (2004) De Nador a Vic, Barcelona, Columna.

Lluch, E. \& T. CABo (2006) Jo Tirant, tu Carmesina, Alzira, Bromera.

Martí, M. \& J. Vila (2004) Paper de diari, Barcelona, La Galera.

Miralles, F. (2002) Un haiku per a l'Alícia, Barcelona, Cruïlla.

Miralles, J. (2005) Matinada de llops, Picanya, Edicions del Bullent.

Mollà, J. \& L. Bosch (2006) Aiguablava, València, Tàndem.

Oliver, A. (2002) El silenci del mariner, Alzira, Bromera.

- (2005) Els caçadors del sol, Barcelona, La Galera.

- (2006) Al-Rhazes, el metge de la talaia, Barcelona, Barcanova.

Pastor, A. \& M. Canals (2005) El nen que feia pondre el sol, Barcelona, Publicacions de l'Abadia de Montserrat.

Pedroso, À. \& T. Peiró (2004) El ninot de neu, Barcelona, Publicacions de l'Abadia de Montserrat.

Pons I Clar, P. (2006) Quan tot comença, Barcelona, Cruïlla.

Portell, R. \& I. Blanch (2005) Vull una corona, Barcelona, La Galera.

PradAs, N. (2002) A carn, a carn!, Barcelona, La Galera.

Prats, J. \& À. FAnlo (2005) El mur i el dragó, Barcelona, Edebé.

Prats, J. \& F. Rovira (2003) Els patins del Sebastià, Barcelona, La Galera.

Rayó, M. \& V. Gubianas (2006) Iosa i les grues, Barcelona, Alfaguara / Grup Promotor.

RaYó, M. \& P. Auladell (2004) El cementiri del capità Nemo, Barcelona, Baula.

Sala Valldaura, J. M. \& C. Julià (2002) Disfresses, Barcelona, La Galera.

Sampere, J. \& M. C. Alcobre (2004) El mar de la tranquil.litat, Barcelona, Cruilla.

Sierra i Fabra, J. (2008) A l'altra banda del mirall, Barcelona, Empúries.

Sotorra, A. (2006) Kor de parallamps, Barcelona, Edebé.

Torró, J. (2003) El justícia, Alzira, Bromera. 